\title{
Isolation and Identification of the Plasma Membrane- Associated Intracellular Protein Reggie-2 from Goldfish Brain by Chromatography and Fourier-Transform Ion Cyclotron Resonance Mass Spectrometry
}

\author{
Sebastian H. J. Bauer, ${ }^{*} \dagger$ Marianne F. Wiechers, ${ }^{*}$ Kai Bruns, $\dagger$ Michael Przybylski, $\dagger^{+1}$ and \\ Claudia A. O. Stuermer* \\ * Department of Biology, Laboratory of Neurobiology, and †Department of Chemistry, Laboratory of Analytical Chemistry, \\ University of Konstanz, 78457 Konstanz, Germany
}

The neuronal protein reggie-2 is localized at the cytoplasmic face of the plasma membrane and participates, together with reggie-1, in the formation of plasma membrane microdomains. Reggie-2 exhibits several potential phosphorylation sites but whether the relevant sites are modified accordingly is not yet known. In order to obtain a detailed, molecular characterization of the primary structure of the native protein, an effective procedure for the isolation of the different reggie proteins from animal tissue is required. The specific properties of the proteins, particularly their membrane association and low abundance, make approaches for isolation such as affinity chromatography and 2D gel electrophoresis unfeasible. This study describes a rapid and efficient procedure for the isolation of reggie-2 by use of two consecutive HPLC steps and subsequent SDS-PAGE. The protein fractions were characterized by SDS-PAGE and Western blot analysis as well as by mass spectrometry. In the primary structure analysis by matrix-assisted laser desorption-ionization mass spectrometry (MALDI-MS), the efficiency of high-resolution Fouriertransform ion cyclotron resonance-MALDI-MS was demonstrated, enabling the direct, unequivocal, and sensitive characterization of posttranslationally and/or chemically modified proteins. () 2001 Academic Press

Key Words: reggie; plasma membrane protein; microdomains; phosphorylation; HPLC; FT-ICR-MS.

\footnotetext{
' To whom correspondence should be addressed.
}

The cellular plasma membrane is highly organized and provides subcompartments called rafts or glycolipidrich microdomains. It has been demonstrated that activated $\mathrm{GPI}^{2}$-anchored cell surface proteins preferentially associate with microdomains and that doubly acylated proteins such as Src family tyrosine kinases are recruited to these sites and trigger signaling cascades (1-3). In neurons, such as dorsal root ganglia and NGF-stimulated PC12 cells, the GPI-anchored cell adhesion proteins F3 and Thy-1 associate upon activation in microdomains which are defined by the presence of the two cell surface proteins, reggie-1 and reggie-2. Reggie-1 and -2 were originally identified as two 50$\mathrm{kDa}$ proteins which are upregulated during retinal axon regeneration in the goldfish visual pathway $(4,5)$. Subsequently, with the generation of reggie-1- and reggie-2-specific antibodies both proteins were found to be localized to the inner leaflet of the plasma membrane in a variety of cell types. Reggie- 1 and reggie- 2 cocluster and are distributed in a punctate pattern when visualized by immunofluorescence microscopy as is typical of microdomains. This is further supported by the fact that activated F3 and Thy-1 cocluster with reggie- 1 and -2 as well as with the src tyrosine kinase

\footnotetext{
${ }^{2}$ Abbreviations used: BSA, bovine serum albumin; EDTA, ethylenediaminetetraacetic acid; FT-ICR, Fourier-transform ion cyclotron resonance; GFC, gel-filtration chromatography; GPI, glycosylphosphatidylinositol; HPLC, high-performance liquid chromatography; HRP, horseradish peroxidase; MALDI, matrix-assisted laser desorption ionization; MS, mass spectrometry; NGF, neuronal growth factor; NHS, $N$-hydroxysuccinimide; OG, octylglucoside; PBS, phosphate-buffered saline; SDS-PAGE, sodium dodecyl sulfatepolyacrylamide gel electrophoresis; TFA, trifluoroacetic acid; TOF, time-of-flight.
} 
fyn (5-7). Both reggie-1 and reggie-2 possess several predicted phosphorylation sites $(5,8)$. It is not known how they associate with the plasma membrane and whether they do indeed undergo posttranslational modifications.

Purification of recombinant reggie- 1 and -2 (containing a His-tag sequence) has been readily achieved by affinity chromatography on a Ni-affinity column (4). However, a procedure for the isolation of native reggie from biological tissues in amounts required for the detailed structural characterization and identification of posttranslational modifications has not been described yet. Conventional affinity chromatography using monoclonal or polyclonal antibodies resulted in poor yields. In the present study we have developed a two-step procedure, using two sequential HPLC columns (gel-filtration and reversed-phase). This procedure provides several advantages such as (i) no additional instrumental requirements for chromatography; (ii) significantly lower loss of protein during the isolation; and (iii) no residual activity of endogenous proteases or phosphatases due to the use of organic solvents in the chromatographic procedure $(9,10)$.

The unequivocal identification of reggie-2 (Fig. 1) has been obtained by mass spectrometric peptide mapping, using matrix-assisted laser desorption ionization (MALDI)-MS. Particularly, the high accuracy of mass determination of high mass resolution Fourier-transform ion cyclotron resonance (FT-ICR) mass spectrometry (11) using a MALDI ion source with pulsed insource ion accumulation (12) provided unequivocal sequence assignments and the direct identification of several phosphorylated and oxidized peptides. In recent studies FT-ICR-MS has been already employed with high performance for the identification of peptide and protein structures and structure modifications (13-15). The results of this study suggest that the purification used may be applicable to other membrane proteins, difficult to purify by conventional affinity chromatography. Furthermore they illustrate the efficiency of high-resolution FT-ICR mass spectrometry for the structural characterization of proteins from biological material.

\section{MATERIALS AND METHODS}

\section{Isolation of Membrane Extract from Goldfish Brain}

A membrane fraction of goldfish brain was isolated by several homogenization and centrifugation steps (5). First, the freshly excised goldfish brains were homogenized in the presence of a mixture of protease inhibitors (Mini-Complete, Novartis, Tutzing, Germany) and $1 \mathrm{mM}$ sodium orthovanadate to inhibit endogenous protease and phosphatase activity. The membrane fraction was isolated by centrifugation of the homogenate on a sucrose step gradient $(20-50 \%$
MFYTCGPNEAMVVSGECRSPPVMISGGSVEVFPCVQQI ORISLNTLTLNV

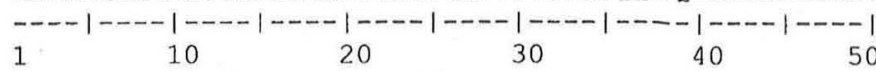
T4-T10
KSDKVYTRHGVPVSVTGIAOMRTOGONKOMTAAKCOMELGKSESDTAHTA

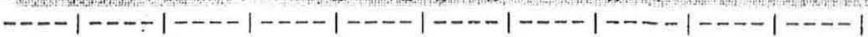
$\begin{array}{lllll}60 & 70 & 80 & 90 & 100\end{array}$ T10-T16

LEMLEGHORAIIAHLTVEEIYKDRKKESEQVFKVASSPLFNMGISVVSYT $-\cdots-1---1-\cdots-1---1-\cdots-1----1----1----1---1-\cdots-1$ $\begin{array}{lllll}110 & 120 & 130 & 140 & 150 \\ \text { T16-T26 } & & \end{array}$

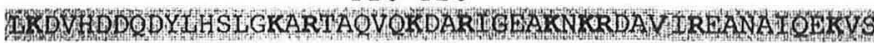
$---1---\mid-\cdots-1---1---1---1---1----1---1---1$ $\begin{array}{lllll}160 & 170 & 180 & 190 & 200\end{array}$ $\mathrm{T} 26-\mathrm{T} 34$

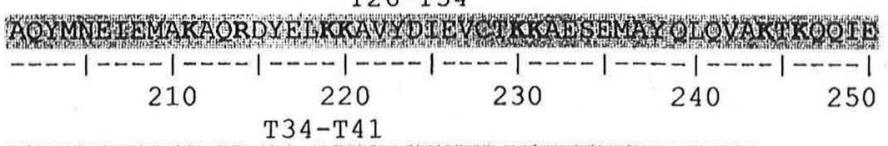

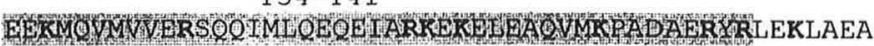

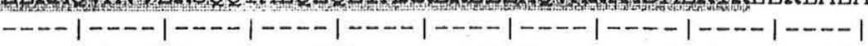
$\begin{array}{llll}260 & 270 & 280 & 290\end{array}$ T 43-44

ERUQWTAASAEAESIKMRGEAEAYAVEARGRAEAEQMAKKAEAFQTYKE $-\cdots-1-\cdots-1-\cdots-1-\cdots-1-\cdots-1-\cdots-1---1---1-\cdots-1-\cdots-1$ $\begin{array}{lllll}310 & 320 & 330 & 340 & 350\end{array}$

GAMVDMLMEKLPLIAEEI SKPLSATNKVTMVSSGGSEI GAAKLTGEVLDI

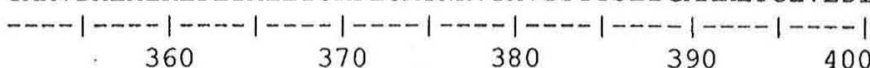

MTKLPETIEKLTGVSISQVARTG

$410 \quad 423$

FIG. 1. Amino acid sequence of reggie-2 translated from the cDNA (cf. Ref. 4). Sequence domains encompassing tryptic fragments identified by mass spectrometry (Table 1) are marked with boldface.

sucrose in PBS) at $10,000 \mathrm{~g}$ and subsequently washed in PBS (including the inhibitor cocktail; centrifugation at $15,000 \mathrm{~g})$. The membrane fraction was then extracted with RIPA buffer (20 mM Tris, $150 \mathrm{mM} \mathrm{NaCl}$, $1 \%$ Triton $\mathrm{X}-100,1 \%$ deoxycholate, $0.1 \%$ SDS, $5 \mathrm{mM}$ EDTA, pH 7.4) by sonication for $1 \mathrm{~h}$ and centrifuged at $100,000 \mathrm{~g}$. A detergent-resistant buoyant fraction as well as the clear extract solution ("RIPA membrane extract," 6-8 ml) were collected. Six to $8 \mathrm{ml}$ of RIPA membrane extract and $1 \mathrm{ml}$ of the "buoyant fraction" were isolated from approximately 90-100 goldfish brains.

\section{HPLC Purification of Proteins}

Two types of reverse-phase columns were used for the purification: Purification of the crude RIPA extract was carried out on an analytical Nucleogel gel-filtration column (GFC-8; $300 \times 7.7$ mM, Macherey-Nagel, Düren, Germany). Elution was performed with $70 \%$ isopropanol and $30 \%$ water in $0.1 \%$ trifluoroacetic acid at a flow rate of $0.4 \mathrm{ml} / \mathrm{min}$. Further purification was 
achieved with an analytical $(250 \times 4.6 \mathrm{mM}) 214 \mathrm{TP}-\mathrm{C} 4$ column (Vydac, Hesperia, CA). Proteins were eluted with a linear gradient (30 to $70 \%$ isopropanol in $0.1 \%$ trifluoroacetic acid over $40 \mathrm{~min}$ ) at a flow rate of 0.8 $\mathrm{ml} / \mathrm{min}$. From $6 \mathrm{ml}$ RIPA extract approximately $1 \mu \mathrm{g}$ of crude reggie- 2 was obtained as estimated from the Coomassie blue-stained gel band.

\section{Protein Characterization by SDS-PAGE and Western Blotting}

One-dimensional SDS-PAGE was carried out according to the method of Laemmli (12). For the characterization of protein fractions by Western blot analysis, $10 \%$ gels were used. For in-gel digestion a precast $4-12 \%$ Bis-Tris gel (NuPAGE, Novex, San Diego, CA) was used with a Mops buffer $(50 \mathrm{mM} 3-(N$-morpholino) propane sulfonic acid, $50 \mathrm{mM}$ Tris, $3.5 \mathrm{mM}$ SDS, 1 mM EDTA) and gel staining with colloid Coomassie blue.

For Western blot analysis the proteins were electrophoretically transferred from SDS gels to nitrocellulose membranes ( $2 \mathrm{~h}$ at $90 \mathrm{~V}$ or overnight at $12 \mathrm{~mA}$ ). The membranes were blocked by incubation with $3 \%$ milk powder in PBST (0.05\% Tween 20 in PBS) for $1 \mathrm{~h}$. For incubation with the primary antibody a monoclonal anti-reggie-2 antibody (R642) (5) was applied for $12 \mathrm{~h}$ at $4^{\circ} \mathrm{C}$ or $2 \mathrm{~h}$ at $25^{\circ} \mathrm{C}$. After washing, the membranes were incubated with horseradish peroxidase (HRP)-conjugated anti-mouse IgG antibody, and immunoreactive bands were visualized with an ECL reagent (Amersham, Pharmacia Biotech, Freiburg, Germany).

\section{In-Gel Digestion and Mass Spectrometric Analysis}

For in-gel digestion and subsequent MALDI-MS analysis the bands were cut out, destained by addition of a $66 \%$ acetonitrile: $34 \%$ water mixture, and incubated for $20 \mathrm{~min}$ at $25^{\circ} \mathrm{C}$. After removal of supernatant and lyophilization of the gel band, a solution of $50 \mathrm{mM}$ $\mathrm{NH}_{4} \mathrm{HCO}_{3}$ was added for rehydration and incubated for $20 \mathrm{~min}$ at $37^{\circ} \mathrm{C}$. This procedure was repeated three times and the final rehydration was performed with the protease solution $(12.5 \mathrm{ng} / \mu \mathrm{l}$ trypsin in $50 \mathrm{mM}$ $\mathrm{NH}_{4} \mathrm{HCO}_{3}$ ). The gel band was incubated for $12 \mathrm{~h}$ at $37^{\circ} \mathrm{C}$, and protein fragments were eluted by the following solvent mixtures, applied sequentially for 30 to 40 min: (i) 5\% acetonitrile/95\% water; (ii) 20\% acetonitrile $/ 80 \%$ water; (iii) $60 \%$ acetonitrile $/ 40 \%$ water. The eluates were combined and concentrated to $5 \mu \mathrm{l}$ without lyophilization to dryness.

MALDI-TOF-MS analysis was carried out with a Bruker Biflex time-of-flight mass spectrometer (Bruker Daltonik, Bremen, Germany) equipped with a Scout MALDI source, UV nitrogen laser, and delayed extraction system. Sample preparation of proteins and analysis using 4-hydroxycinnamic acid (HCCA) as matrix was as previously described (17). MALDI-FTICR-MS was performed with a Bruker Apex II FT-ICR instrument equipped with an actively shielded 7T superconducting magnet, a cylindrical INFINITYR ICR analyzer cell (18), and an external MALDI source with pulsed collision gas (12). The pulsed nitrogen laser is operated at $337 \mathrm{~nm}$, and ions are directly desorbed into a hexapole ion guide while being cooled during formation using $\mathrm{Ar}$ as the collision gas. Ions generated by five laser shots were accumulated in the hexapole at $15 \mathrm{~V}$ and extracted at $-7 \mathrm{~V}$ into the analyzer cell. A 10 $\mathrm{mg} / \mathrm{ml}$ solution of 2,5-dihydroxybenzoic acid (DHB, Aldrich, Germany) in $0.1 \%$ trifluoroacetic acid in water: acetonitrile (2:1) was used as the matrix. One microliter of matrix solution and $1 \mu \mathrm{l}$ of sample solution were mixed on the stainless-steel MALDI sample target and allowed to dry. Calibration was performed with a standard peptide mixture with an $m / z$ range of approximately $5000(14,18)$. Mass determination accuracy was typically ca. $1 \mathrm{ppm}$, at a resolution of 100,000 as employed for the analysis of reggie.

\section{RESULTS AND DISCUSSION}

Several attempts to isolate reggie from different membrane extracts (RIPA, $n$-octylglucoside (OG)) by affinity chromatography (using various specific antibodies) did not yield satisfactory results. Although reggie could be immunoprecipitated with a polyclonal (R572) as well as with a monoclonal (R642) antibody, only poor yields of reggie could be isolated from the membrane extracts. Western blot analysis (not shown) of the immunoprecipitated material, in comparison to the different washing fractions, showed that only a small proportion of the protein $(\leq 10 \%$ as estimated by comparison of Western blot bands before and after immunoprecipitation) could be precipitated with either monoclonal or polyclonal antibodies. A possible explanation for the inefficiency of the immunoprecipitation may be the formation of multimeric association complexes which might shield the epitope against the paratope of the antibody thus resulting in low affinity and hence only uncomplexed monomer would be efficiently bound by the immobilized antibody. This assumption was corroborated by some improvement of the precipitation observed upon using a "harsher" detergent (RIPA) in comparison to OG, which would be expected to provide an increase of monomeric molecules in solution. However, due to the concomitant effect of enhanced antigen-antibody complex dissociation under harsh solvent conditions, a further optimization by using denaturing solvent conditions was not achieved. Furthermore, at these conditions affinity chromatography using the covalently (NHS-Sepharose) bound anti- 


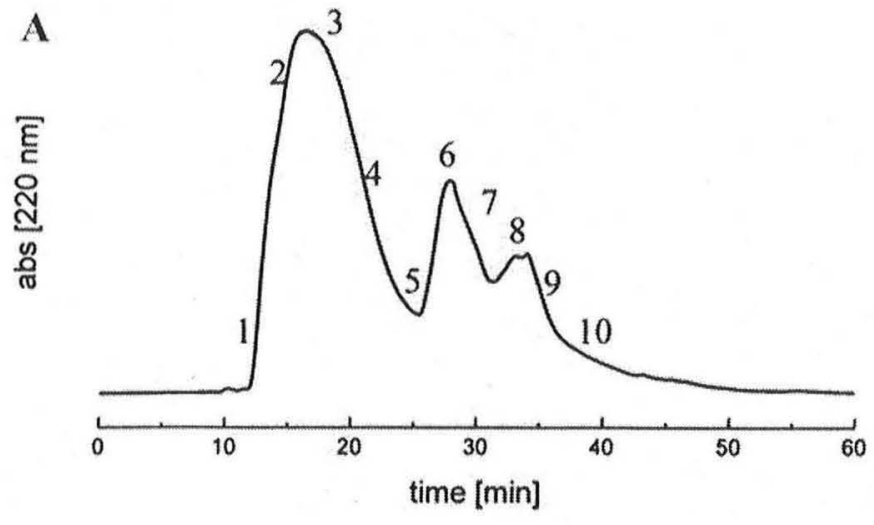

B

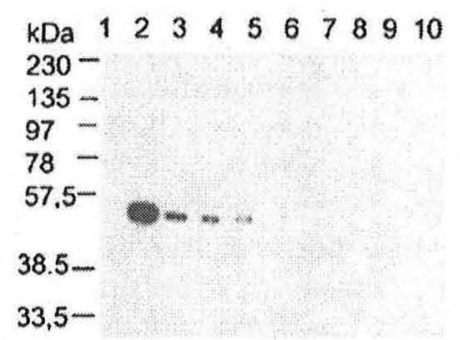

FIG. 2. (A) GFC-HPLC purification of crude "RIPA extract" from goldfish brains membrane fraction. (B) Western blot analysis of collected fractions using the monoclonal anti reggie- 2 antibody R642 (cf. Ref. 5).

reggie antibody $\mathrm{R} 642$ did not show specific binding of protein, thus prompting our efforts to develop an alternative chromatographic purification procedure. Appropriate HPLC approaches had been previously shown to be successful in the purification of membrane proteins $(19,20)$.

As the first step of the new procedure, the RIPA membrane extract was directly applied on an analytical gel-filtration (GFC)-HPLC column. In this manner the size-exclusion chromatography serves as an initial purification step of the crude extract, as well as for changing the solvent system (to an isopropanol/water/ TFA mixture) with simultaneous removal of detergent which would significantly decrease the performance of the reversed-phase HPLC column in the second purification step. Figure 2A shows a typical gel-filtration chromatogram of the crude RIPA membrane extract, using isocratic solvent elution with $70 \%$ isopropanol, $30 \%$ water, and $0.1 \%$ trifluoroacetic acid. A lower content of isopropanol than $70 \%$ in the gel-filtration chromatography step resulted in significantly reduced recovery rates for reggie as estimated by comparison of Western blot bands before and after chromatography. Furthermore, increased recoveries were obtained by diluting the membrane extract with HPLC solvent before application to the column; typically $300 \mu 1$ of membrane extract was diluted with $700 \mu \mathrm{l}$ of the HPLC solvent. In this manner 10 fractions were collected (Fig. 2A) and subjected to Western blot analyses using the monoclonal anti-reggie-2 antibody R642 (Fig. 2B). The Western blot analysis clearly showed that reggie-2 was eluted in fractions 2-5 (corresponding to the first major peak), with the majority being eluted in fraction 2 .

The second purification step was performed by application of the combined fractions 2-4 (Fig. 2A, concentrated from $2 \mathrm{ml}$ to $200 \mu \mathrm{l}$ ) on an analytical reversed-phase HPLC column. A typical chromatogram is shown in Fig. 3A. Seventeen fractions were collected and subjected to Western blot analysis using the monoclonal anti reggie- 2 antibody R642 as detecting antibody (Fig. 3B). Reggie-2 was exclusively eluted in fractions 9-11, the majority of which mainly in fractions 10 and 11 . To check purity and amount of protein, an SDS gradient gel was run and stained by colloid Coomassie blue staining. Figure $3 \mathrm{C}$ shows a gel to which 10 combined fractions of reggie (lane 2) were applied after HPLC separation, corresponding to about $2 \mathrm{ml}$ RIPA membrane extract (approximately 30 goldfish brains). The most intensive band (lane 2) showed an apparent molecular weight corresponding to the amino acid sequence molecular weight of reggie-2 $(50 \mathrm{kDa})$. To estimate the amount of isolated reggie-2, reference amounts of $1 \mu \mathrm{g}, 0.1 \mu \mathrm{g}$, and $0.01 \mu \mathrm{g}$ of bovine serum albumin (BSA) were applied to lanes 3-5, respectively. The intensity of the reggie- 2 band corresponded to about $1 \mu \mathrm{g}$ BSA (lane 3). Thus, it can be estimated that approximately $1 \mu \mathrm{g}$ of reggie-2 was isolated from 30 goldfish brains.

The amount of protein recovered (ca. $1 \mu \mathrm{g}$ ) was sufficient to perform mass spectrometric peptide mapping analyses after in-gel digestion of a Coomassie-stained gel band (21). The gel band shown in Fig. 3C (lane 2) was cut out and digested with trypsin and the resulting peptide fragment mixture was analyzed by MALDITOF-MS as well as by high-resolution MALDI-FTICR-MS on the Bruker Apex II 7T FT-ICR mass spectrometer (see Fig. 4). Twenty-four peptide ions were unequivocally assigned to tryptic fragments of reggie-2 from the high-resolution FT-ICR-MS data; the MALDITOF-MS analysis provided a similar number of peptide ions but peptides found were only assignable to unmodified partial sequences (data not shown). A database search using the SwissProt sequence database did not reveal any other proteins with a comparably high identification score. However, a significant number of the detected ions could not be assigned to the unmodified amino acid sequence of reggie-2. These ions may originate from impurities from the gel band excised and from possible modifications of reggie- 2 and/or degradation products from the MALDI-FT-ICR-MS conditions (16). The peptide ions identified, mass determination accuracies obtained by FT-ICR-MS, and assignments of modifications are summarized in Table 1. Several 
A

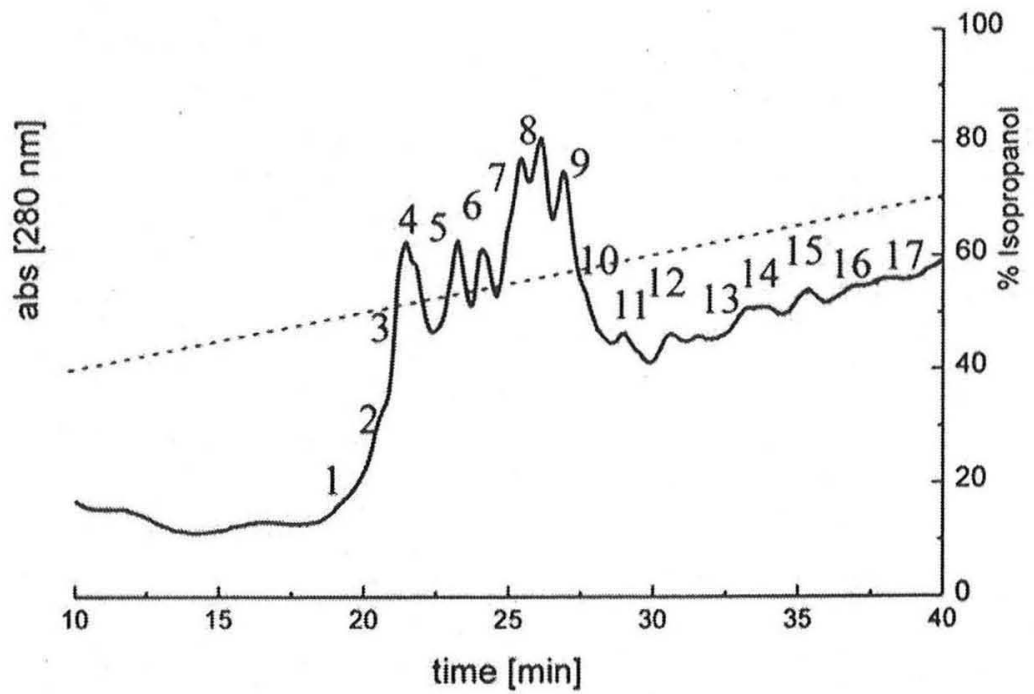

B

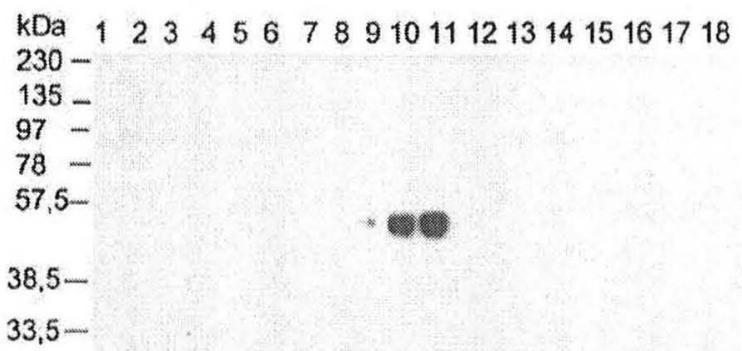

C

$123456 \quad \mathrm{kDa}$

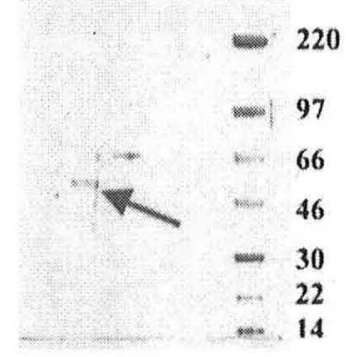

FIG. 3. (A) C4-RP-HPLC purification of fraction 2 (Fig. 2A). (B) Western blot analysis of fractions using a monoclonal anti reggie-2 antibody (R642). (C) Coomassie-stained Tris-gradient gel. Combined fraction from lanes 10 and 11 in (B) were applied in lane 2. The arrow marks the band corresponding to reggie-2. In lanes $3-5,1,0.1$, and $0.01 \mu \mathrm{g}$ bovine serum albumin were applied, respectively.

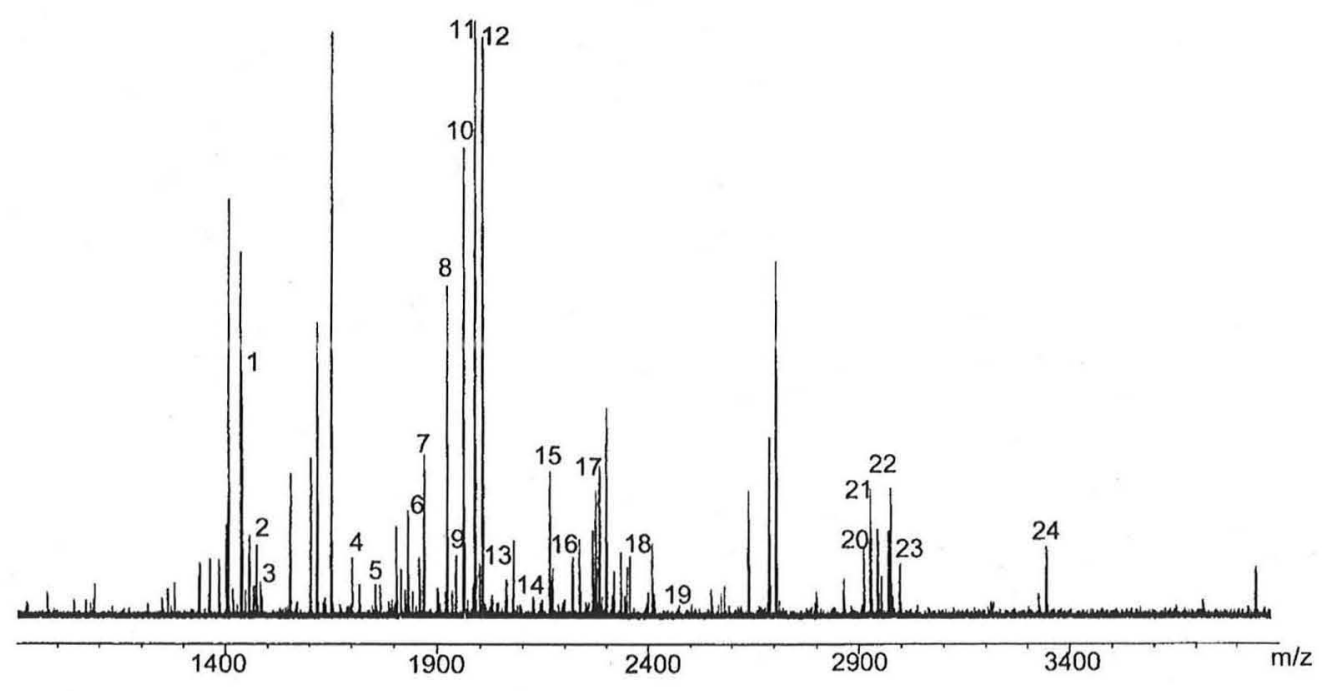

FIG. 4. MALDI-FT-ICR mass spectrum of the in-gel digested (trypsin) gel band of reggie-2 (Fig. 3C, lane 2). The signals identified as fragments of reggie-2 are marked with numbers and are summarized in Table 1. P, phosphorylated peptide; O, Met-oxidized peptide. 
TABLE 1

Peptide Fragments of Reggie-2 by Tryptic In-Gel Digestion/MALDI-FT-ICR-MS

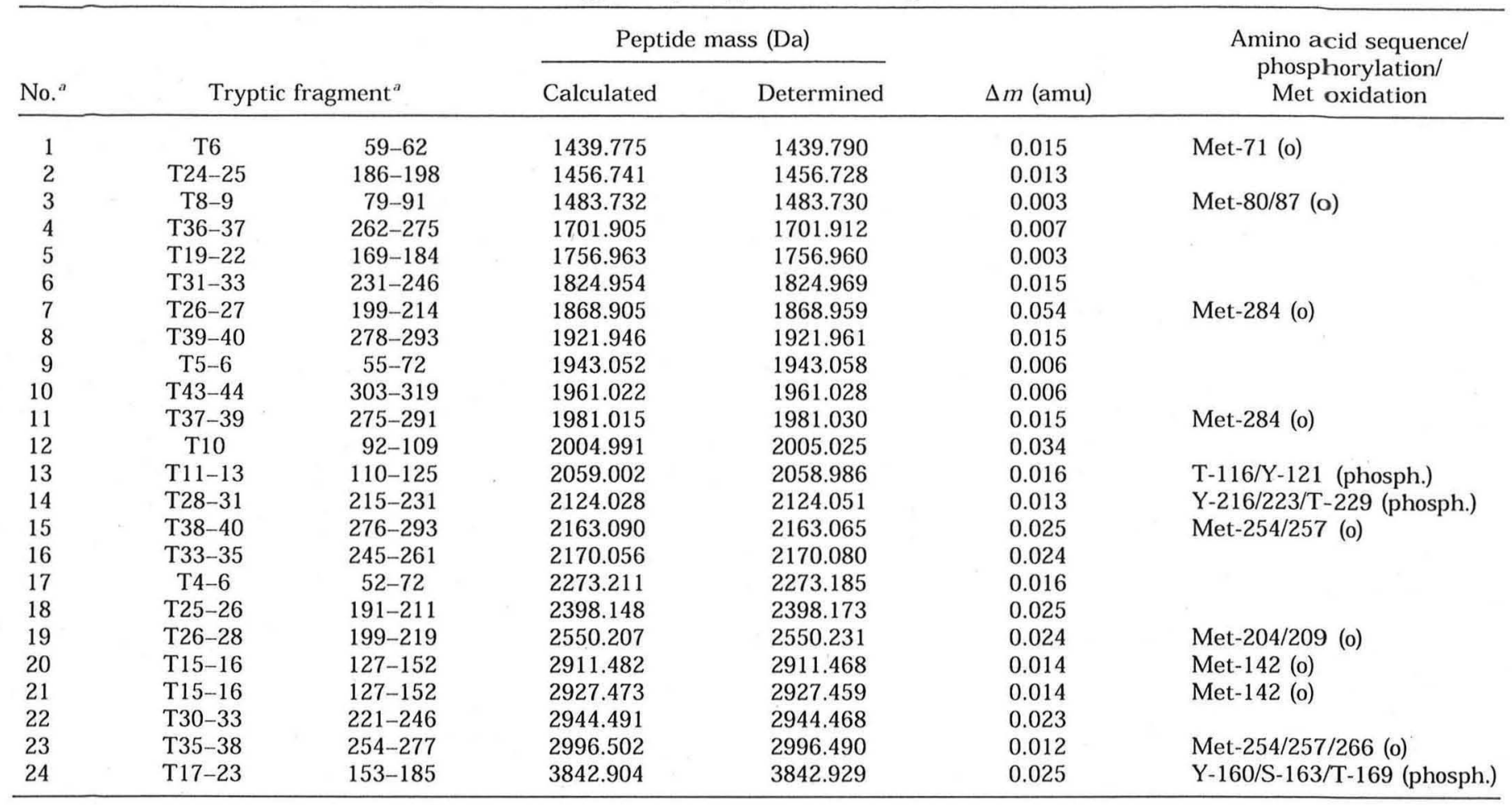

${ }^{a}$ Numbers according to Fig. 4 .

modifications were found by oxidation of methionine residues to sulfoxide or sulfone derivatives, respectively, which may result from the in-gel digestion procedure (22). The abundance of these oxidized fragments may be explained by the unusually large number of methionine residues (22) in the reggie-2 sequence. Furthermore, the accurate mass assignments (typically $\leq 10 \mathrm{ppm}$ ) provided the identification of three phosphorylations within the sequence positions (110-125), (158-185), and (215-231) at either Thr or Tyr residues. Additional fragments (not assigned in Table 1) were found with mass differences of +1 amu which clearly point to hydrolysis at Gln or Asn to Glu and Asp, respectively, such as Q-337. These modifications (possibly resulting from the isolation procedure) will be established in subsequent studies by protein sequence data.

\section{CONCLUSIONS}

In view of the current interest in the structural as well as important biological features of the reggie proteins (4), the development of an effective isolation procedure from native tissue is highly desirable. Reggie-2, as well as other membrane-associated proteins, could be isolated only with poor yields by affinity chromatography, which frequently is the fastest and most effi- cient method of isolation. On the other hand, a direct characterization of a protein by 2D gel electrophoresis, subsequent in-gel digestion, and mass spectrometric peptide mapping analysis is only possible if the concentration of the protein is high enough to yield a visible gel spot (21). The rapid and direct procedure developed in this study consists of two consecutive HPLC chromatographic steps, followed by a simple SDS-PAGE gel electrophoresis. An advantage of the described procedure is its applicability to other proteins of similar molecular properties, such as hydrophobic microdomain-associated membrane proteins. Other proteins that cannot be purified by conventional affinity chromatography may also be purified efficiently by this procedure.

The results of the MALDI-FT-ICR-mass spectrometric data clearly illustrate the potential of the high mass determination accuracy of the high-resolution FT-ICR method for unequivocal protein identification and sequence characterization, even in the presence of impurities and/or modifications. At mass assignment accuracies of $10 \mathrm{ppm}$ or better, modifications by phosphorylation and oxidation were directly identified which were not possible to detect by MALDI-TOF-MS. These results also illustrate the performance of the MALDI-FT-ICR source with pulsed gas collision, al- 
though at present these and other recent data were only obtained with DHB as a "soft" matrix, and some peptide fragmentation could not be ruled out. Corresponding FT-ICR-MS studies for the identification of structure modification of reggie are in progress in our laboratory.

\section{ACKNOWLEDGMENTS}

We thank Dr. Matthias Witt and Dr. Goran Baykut (BrukerDaltonik, Bremen, Germany) for assistance with the MALDI-FTICR-source. This work was supported by grants from the Deutsche Forschungsgemeinschaft (DFG) (to C.A.O.S.; and to M.P., high resolution Biopolymer-MS program and instrument grant), the State Baden-Württemberg (competence center for proteome analysis), and the Fonds der Chemischen Industrie, Frankfurt, Germany.

\section{REFERENCES}

1. Simons, K., and Ikonen, E. (1997) Functional rafts in cell membranes. Nature 387, 569-572.

2. Brown, D. A., and London, E. (1998) Function of lipid rafts in biological membranes. Annu. Rev. Cell. Dev. Biol. 14, 111-136.

3. Harder, T., Scheiffele, P., Verkade, P., and Simons, K. (1998) Lipid domain structure of the plasma membrane revealed by patching of membrane components. J. Cell Biol. 141(4), 929942.

4. Schulte, T., Paschke, K., Laessing, U., Lottspeich, F., and Stuermer, C. A. O. (1997) Reggie-1 and reggie-2, two cell surface proteins expressed by retinal ganglion cells during axon regeneration. Development 124, 577-587.

5. Lang, D. M., Lommel, S., Jung, M., Ankerhold, R., Petrausch, R., Laessing, U., Wiechers, M., Plattner, H., and Stuermer, C. A. O. (1998) Identification of reggie-1 and reggie-2 as plasma membrane-associated proteins which co-cluster with GPI-linked cell adhesion molecules in noncaveolar microdomains. J. Neurobiol. 37, 502-523.

6. Stuermer, C. A. O., Plattner, H., Lang, D. M., and Kirsch, F. (2001) Exploring the function of reggie-1 and reggie-2, components of non-caveolar plasma membrane microdomains. Mol. Biol. Cell, in press.

7. Lang, D. M., Kirsch, F., Wiechers, M., Plattner, H., and Stuermer, C. A. O. (2001) GPI-anchored proteins and fyn kinase assemble in non-caveolar plasma membrane microdomains defined by reggie- 1 and -2 . Submitted for publication.

8. Bickel, P. E., Scherer, P. E., Schnitzer, J. E., Oh, P., Lisanti, M. P., and Lodish, H. F. (1997) Flotillin and epidermal surface antigen define a new family of caveolae-associated integral membrane proteins. J. Biol. Chem. 272(21), 13793-13802.

9. Bauer, S. H., Zhang, X. Y., Liang, F., De Potter, W. P., Claeys, M., and Przybylski, M. (1997) Isolation and identification of intact chromogranin $\mathrm{A}$ and two $\mathrm{N}$-terminal processing products, vasostatin I and II, from bovine adrenal medulla chromaffin granules by chromatographic and mass spectrometric methods. Neuropeptides 31(3), 273-280.

10. Brunden, K. R., Berg, C. T., and Poduslo, J. F. (1987) Isolation of an integral membrane glycoprotein by chloroform-methanol extraction and C3-reversed-phase high-performance liquid chromatography. Anal. Biochem. 164(2), 474-481.

11. Marshall, A. G., Hendrickson, C. L., and Jackson, G. S. (1998) Fourier transform ion cyclotron resonance mass spectrometry: A primer. Mass Spectrom. Rev. 17(1), 1-35.

12. Laemmli, U. K. (1970) Cleavage of structural proteins during the assembly of the head of bacteriophage T4. Nature 227, 680-685.

13. Fligge, T. Przybylski, M., Quinn, J. P., and Marshall, A. G. (1998) Evaluation of heat-induced conformational changes in proteins by nanoelectrospray Fourier transform ion cyclotron resonance mass spectrometry. Eur. Mass Spectrom. 4, 401-404.

14. Maccarone, G., Seidl, A., and Przybylski, M. (2001) Mass spectrometric identification, structural characterisation and stability of a non-covalent dimer complex of lung surfactant protein SP-C. Fres. J. Anal. Chem., in press.

15. Fligge, T. A., Reinhard, C., Harter, C., Wieland, F. T., and Przybylski, M. (2000) Oligomerization of peptides analogous to the cytoplasmic domains of coatamer receptors revealed by mass spectrometry. Biochemistry 39, 8491-8496.

16. Baykut, G., Jertz, R., and Witt, M. (2000) Matrix-assisted laser desorption/ionisation Fourier transform ion cyclotron resonance mass spectrometry with pulsed in-source collision gas and insource ion accumulation. Rapid Commun. Mass Spectrom. 14, $1238-1247$.

17. Denzinger, T., Przybylski, M., Savoca, R., and Sonderegger, P. (1997) Mass spectrometric characterisation of primary structure, sequence heterogeneity, and intramolecular disulfide loops of the cell adhesion protein axonin-1. Eur. Mass Spectrom. 3, 379-389.

18. Damoc, E., Bruns, K. Youhnovski, N., Buehler, S., Seidl, A., and Przybylski, M. (2001) Mass spectrometric approaches to proteome analysis with high resolution and high selectivity. Electrophoresis, in press.

19. Kawakami, T., Suzuki, T., Baek, S. H., Chung, C. H., Kawasaki, H., Hirano, H., Ichiyama, A., Omata, M., and Tanaka, K. (1999) Isolation and characterization of cytosolic and membrane-bound deubiquitinylating enzymes from bovine brain. J. Biochem. (Tokyo) 126(3), 612-623.

20. Gondolf, K. B., Batsford, S. R., and Vogt, A. (1990) Isolation of an outer membrane protein complex from Borrelia burgdorferi by n-butanol extraction and high-performance ion-exchange chromatography. J. Chromatogr. 521(2), 325-334.

21. Jensen, O. N., Larsen, M. R., and Roepstorff, P. (1998) Mass spectrometric identification and microcharacterization of proteins from electrophoretic gels: Strategies and applications. Proteins Suppl. 2, 74-89.

22. Reid, G. E., Rasmussen, R. K., Dorow, D. S., and Simpson, R. J. (1998) Capillary column chromatography improves sample preparation for mass spectrometric analysis: Complete characterization of human alpha-enolase from two-dimensional gels following in situ proteolytic digestion. Electrophoresis 19(6), 946-955. 